\title{
Grandparents Raising Grandchildren: Tips for Navigating the System ${ }^{1}$
}

Maisie Ross, Larry Forthun, Millie Ferrer-Chancy, and Angela Falcone ${ }^{2}$

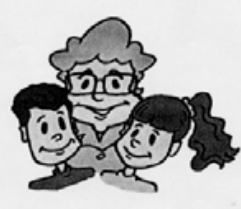

Goal: To provide grandparents with information and skills necessary to use various community resources.
Financial Assistance (FCS2188a) Health Care Assistance (FCS2188b) School and Educational Assistance (FCS2188C) Custody Options (FCS2189)

\section{Developing Your Plan}

Many grandparents are not aware of or are unable to effectively use community resources. If you want help, you will need to develop a plan of action which includes the following steps:

1. Identify and list the problems you are having. Try to be as specific as possible as you list the problems you are facing and how they impact your ability to care for your grandchildren. For example:

"When my grandchildren get sick, they need to see a doctor. I can't afford to pay for an office visit for each grandchild, so I stay home from work to take care of them. That also means less money in my paycheck at the end of the month."

2. Write down the barriers that are preventing you from getting the help you need. A barrier is any obstacle that you feel will keep you from getting what you need. For example:

"My grandchildren need health care but my employer won't pay for it and I can't afford to pay for it on my own."

3. Create a plan to search for available community resources that match your needs and overcome your barriers. Begin by reading the other publications in this series and then list the things that you will do to search out the resources that you need. For example:

1. This document is FCS2188, one of a series of the Department of Family, Youth and Community Sciences, Florida Cooperative Extension Service, Institute of Food and Agricultural Sciences (IFAS), University of Florida. First published: December 2002. Revised: August 2009. Please visit the EDIS Web site at http://edis.ifas.ufl.edu.

2. Maisie Ross, Family and Consumer Sciences, West Palm Beach County Extension, 559 N. Military Trail, West Palm Beach, 33415; Larry F. Forthun, Ph.D., assistant professor, Department of Family, Youth and Community Sciences, Institute of Food and Agricultural Sciences, University of Florida, Gainesville, FL 32611; Millie Ferrer-Chancy, Ph.D., interim dean, Florida Cooperative Extension Service, University of Florida; and, Angela Falcone, former FYCS graduate student of University of Florida. 
a. Go to the Florida KidCare Web site and read about the health care options that are available for children. http://floridakidcare.org

b. Request a KidCare application and read the instructions thoroughly so that I know what kind of documentation is required. I don't want to mail the application and find out later that I forgot something and will have to fill it out again.

c. If I need help, I will call my local Medicaid office.

\section{Preparing for the Search}

It can be difficult and time consuming to search for needed resources. It is important that you think clearly about what you need and must do. You will need to learn how to work with public systems such as schools, child welfare, health, and legal aid. Keep in mind that many of these systems were not originally set up to recognize grandparents raising their grandchildren.

You can develop qualities to be better prepared for your search. According to the Grandparent Resource Center, you need to be...

1. Confident - If you qualify for a service, you have the right to use it. Ask for what you need and say it with confidence.

2. Organized - People will take you more seriously if you are organized. You will be more effective if you...

- make a list of the agencies that best fit your needs.

- $\quad$ write down the phone number(s).

- locate a contact person.

- prepare questions to ask on the phone or in person.

- $\quad$ are on time for all appointments.

- write down what you were told and the name of the person with whom you met, and the date.

3. Persistent - Don't give up. Keep looking and asking questions. One person may tell you he can't help, but sure enough, someone else at the same agency usually can.

4. Energetic - Take care of yourself. Get enough rest so your mind will be alert. Be enthusiastic when you ask for and receive help.

5. Well Prepared - Have the following documents:

- your grandchild's birth certificate
- $\quad$ proof of caretaker responsibility, (e.g., a statement from the parent or any legal document)

- child's social security number

- proof of income for household members

- proof of ownership, (e.g., house deed, title of car)

- your household expenses, (e.g., mortgage payments or rent receipts, utility bills)

\section{Where to Search}

There are a number of resources available to you. These include both government and private agencies. Some of these are universities, senior centers, and schools. You can also look for help in faith-based groups and

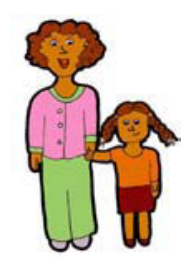
support groups. Fees for these services range in price. Government services are usually free or cost very little.

As you search your community, you will find resources to assist you. These resources can help you with your financial, health, childcare, or educational needs.

\section{Where to get help!}

\section{Kinship Care Warmline (800) 640-6444}

This toll-free line provides information, referrals, and emotional support to kinship caregivers.

\section{United Way Information and Referral (800) 411-8929}

This service, which has a list of all your community resources, links you to local information and referrals. State what you need and this will help match you to the appropriate resource.

\section{References:}

Grandparent Resource Center, New York City Department for Aging. For Grandparents Raising Grandchildren: A Series of Workshops to Help You Cope.

Grandparent Resource Center

NYC Department for the Aging

2 Lafayette Street

New York, NY 10007-1392

(212) 442-1094 or (212) 442-1100 